\title{
Trace Metals Screening Process of Devices Used for the Collection, Analysis, and Storage of Biological Specimens
}

\author{
Cynthia D. Ward ${ }^{\mathrm{a}, \mathrm{b}}$, Reba J. Williams ${ }^{\mathrm{a}}$, Katelyn Mullenix ${ }^{\mathrm{b}}$, Kristy Syhapanha ${ }^{\mathrm{b}}$, \\ Robert L. Jones ${ }^{a}$, and Kathleen Caldwell ${ }^{\mathrm{a}}$ \\ a Centers for Disease Control and Prevention, National Center for Environmental Health, \\ Division of Laboratory Sciences, Inorganic \& Radiation Analytical Toxicology Branch, \\ 4770 Buford Highway NE MS F-50, Atlanta, GA 30341-3717, USA \\ b Oak Ridge Institute for Science and Education, \\ 4770 Buford Highway NE MS F-50, Atlanta, GA 30341-3717, USA
}

\section{INTRODUCTION}

Over the last two decades, the Centers for Disease Control and Prevention's (CDC) Inorganic and Radiation Analytical Toxicology Branch (IRATB) has transitioned from using graphite furnace atomic absorption (GFAA) to using inductively coupled plasma mass spectrometry (ICP-MS) to quantify the metal content of various biological matrices. ICP-MS enables accurate quantification of ultra trace levels of numerous toxic and essential metals simultaneously for biomonitoring studies. We also use our analytical methods to assess human exposures to trace, toxic, and essential metals in emergency response situations (i.e., acute exposures) and, as part of biomonitoring studies, for targeted populations of interest. The analytical data from emergency response samples help to determine the specific source of exposure and drive treatment decisions, while data from biomonitoring studies help identify exposures among targeted populations and contribute to national public health policy decisions, and also guide diagnosis and treatment decisions for specific diseases caused by exposure to these metals (1). The data obtained from our laboratory's measurements as part of the National Health and Nutrition Examination Survey (NHANES) are summarized in the National Report on Human Exposure to Environ-

\footnotetext{
*Corresponding autbor.

E-mail: CWard@cdc.gov

Tel: +1-770-488-7302

Fax: +1-770-488-0509
}

\section{ABSTRACT}

The Centers for Disease Control and Prevention's (CDC) Environmental Health Laboratory uses modified versions of inductively coupled plasma mass spectrometry (ICP-MS) analytical methods to quantify metals contamination present in items that will come into contact with patient samples during the preanalytical, analytical, and postanalytical stages. This lot screening process allows us to reduce the likelihood of introducing contamination which can lead to falsely elevated results. This is particularly important when looking at biomonitoring levels in humans which tend to be near the limit of detection of many methods. The fundamental requirements for a lot screening program in terms of facilities and processes are presented along with a discussion of sample preparation techniques used for lot screening. The criteria used to evaluate the lot screening data to determine the acceptability of a particular manufacturing lot is presented as well. As a result of lot testing, unsuitable manufactured lots are identified and excluded from use.

mental Chemicals. In this report, the CDC continuously updates reference levels for the United States population for exposures to various toxic and essential metals of concern (2). The analytical data that our laboratory generates for other biomonitoring studies are used to answer specific questions for targeted populations. Considering the public health significance of these data, it is essential that quality remain a cornerstone of our laboratory's analytical measurements. The quality of our measurements is a reflection of the techniques employed, the skill of our scientists, and the materials used in the process. Seemingly small amounts of contamination could skew analytical results to the point where the perceived patient exposure level can lead to erroneous conclusions, treatment recommendations, and policy decisions (3). The process of lot screening, also referred to as lot testing, enhances the ability to obtain an accurate exposure assessment by minimizing the risk of contamination from sample collection and laboratory devices. Emphasis is typically placed upon the laboratory analyst not introducing errors during the analytical process, but the introduction of contamination during the pre-analytical processes is often overlooked.

In the 1980's, we started incorporating the lot screening process into our analytical systems. We use modified versions of our routine analytical methods to assess the metals content in manufactured lots of materials used for the collection, analysis, and storage of biological specimens undergoing trace metals analyses. We screen manufactured lots for lead $(\mathrm{Pb})$, cadmium (Cd), mercury (Hg), selenium (Se), and manganese (Mn), and also chromium (Cr) and cobalt (Co) when applicable. Serum-related items are screened for zinc ( $\mathrm{Zn}$ ), copper $(\mathrm{Cu})$, and/or selenium. 
Items related to the collection, analysis, and storage of urine samples are screened for the following metals: antimony (Sb), arsenic (As), barium $(\mathrm{Ba})$, beryllium (Be), cadmium, cesium (Cs), chromium, cobalt, iodine (I), lead $(\mathrm{Pb})$, molybdenum (Mo), manganese, mercury, nickel $(\mathrm{Ni})$, platinum $(\mathrm{Pt})$, strontium (Sr), thallium (Tl), tin (Sn), tungsten (W), and uranium (U) $(4,5)$. Analytes such as lead, barium, and manganese are more problematic than others. Using materials that have metals concentrations below thresholds defined by our biomonitoring requirements provides assurance that the analytical results obtained are indeed a result of the patient specimen itself and are not falsely elevated because of contamination from items used in the collection and analytical process.

Our lot screening efforts have evolved over the years. CDC scientists currently use inductively coupled plasma mass spectrometry (ICP-MS) and modified versions of our routine analytical methods for biological specimens to determine the amount of metals contamination present in items that will come into contact with patient samples during the pre-analytical, analytical, and post-analytical stages. In 2005, we established a dedicated laboratory to focus solely on lot screening analyses. Between 2002 and the present, IRATB has seen an increase in both the number of items screened and the analytical methods utilized within our laboratory. The literature contains a few references to the concept of lot screening, but our laboratory provides a comprehensive, dedicated lot screening program geared towards all aspects of the analytical process: sample collection, processing, sample analysis and handling within the laboratory, and sample storage (6). The process utilized is explained in this manuscript. A discussion of lot screening results obtained over a 14-year time period is provided as well. The results obtained validate the necessity of performing lot testing to obtain accurate measurements that are not biased due to contamination.

\section{EXPERIMENTAL}

\section{Background}

We perform lot screening analyses on manufactured lots of materials purchased for use in our laboratory and for use in field studies, including materials used for CDC's blood metals, serum, and urine methods. We also screen materials purchased directly by our collaborators for large studies such as NHANES when the biological specimens will be submitted to our laboratory for metals analysis. An alternative to lot screening would be to acid wash devices or containers before use; however, the high sample throughput for our analytical methods eliminates the practicality of acid washing individual items. Acid washing is not feasible for all types of devices and containers for a number of reasons. For items that can be acid washed, the process is too time-consuming considering the workflow within the laboratory. Other items, such as evacuated blood and serum tubes cannot be acid washed because the vacuum would have to be broken to do so. Additionally, devices that contain anti-coagulants and preservatives cannot be acid washed because acid washing would remove the anti-coagulant or preservative.

Potential sources of metals contamination introduced during manufacturing processes include materials used to make the devices (glass, stainless steel, rubber, or plastic), colorants, preservatives used in collection devices, and the manufacturing machinery. The conditions of the manufacturing processes involved in the production of commercial devices can differ with each batch (or "lot") of materials produced; therefore, the amount of contamination introduced can vary from lot to lot making it necessary to test materials from each manufactured lot that will be used in the analytical process.

\section{Requirements for a Lot Screening Program}

We have identified four fundamental laboratory requirements that need to be in place prior to implementation of an effective metals lot screening program. First, the laboratory needs to have analytical methods developed and implemented that allow the analysts to measure ultra trace concentrations of the metals of concern in aqueous solutions. Second, the laboratory needs to have access to a "clean" environment. Devices should be prepared for testing inside of a laminar flow hood Class 100 or better to reduce the likelihood of exposure to external contamination of the items being screened. The third requirement is precautionary measures that ensure analysts performing lot testing are not introducing contamination into the process. These measures include, but are not limited to, using clean powderfree gloves to handle the devices, minimizing the handling of the devices to be screened, ensuring that reagents used in the process are free from contaminants, and ensuring that clean metals-free equipment is used throughout the steps of the screening process. The fourth requirement is having a system in place to evaluate and track the results. Our screening program exceeds these four requirements. Our laboratory uses a dedicated clean room for lot testing. The room falls under ISO 14644-1 class ISO 6 which is equivalent to the FED STE 209E class 1,000 designation (7). We use class II type A2 biological safety cabinets within this room to prepare samples in. All analytical instruments and 
equipment used are dedicated to lot screening; the lot screening instrumentation and equipment is never exposed to biological matrices. In addition to focusing on the fundamentals, we periodically evaluate the analytical methods used to assess efficiency and best practices. We use extensive preventative maintenance and cleaning protocols to maintain all lot screening analytical instruments and equipment. All reagents are prepared in acid-washed containers that have been thoroughly rinsed with $\geq 18$ $\mathrm{M} \Omega$-cm deionized water. Rinsate from the cleaned containers is analyzed to ensure that residual contamination is not present after cleaning. The reagents used and solutions made are screened using the ICP-MS to ensure that they are not contaminated. For this screening, we analyze a dilution of the reagent or the solution itself to compare the counts per second obtained to those of a blank or deionized water. If reagents have analytes present at levels higher than we typically see in our reagent blanks, we seek alternate sources for the reagents.

\section{Lot Screening Process}

Our laboratory maintains a supply of pre-screened materials on hand for use in field studies and emergency response situations. We evaluate manufactured lots of vacuum-sealed evacuated blood tubes, vacuum-sealed serum tubes, needles (18G, 21G, 23G, and 25G), luer adapters, syringes, cryogenic vials, centrifuge tubes, urine collection cups, pediatric urine collection bags, disposable transfer pipets, pipette tips, alcohol pads and wipes, among other items. Our preference is to provide our prescreened materials, whenever possible, to eliminate possible bias in analytical results from our external collaborators using contaminated specimen collection materials. When collaborators purchase their own materials for use, we ask that they send a portion of each manufacturing lot to our laboratory for screening prior to sample collection. We provide standardized request forms to each entity requesting screening services to ensure that pertinent information is captured for each manufactured lot. From every manufactured lot, our laboratory screens 50 units, ensuring that no more than $5 \%$ of the units can be expected to be defective in an acceptable lot with a $90 \%$ confidence. The basis for testing 50 units from each lot was statistically derived (8). First, a screening solution is tested for the analytes of interest, and only a solution that is known not to have analyte concentrations above the analytical method limits of detection is used in the screening process. The screening solution is then added to or passed through laboratory devices, and the solution is subsequently tested to determine if the analytes of interest are present. If the analysis of the solution after contact with the device shows the presence of contamination at levels that are unacceptable, the lot is deemed unsuitable and is not used.

Some laboratory consumables, such as storage vials and collection devices, come with certifications from the manufacturers about their metals content. Only specific metals are tested, so data for all of our analytes of concern is not available. Another problem with the vendorprovided certifications is that the levels at which these items are certified is significantly higher than the low parts per billion (ppb) and parts per trillion (ppt) levels that are of concern with biomonitoring measurements. In most instances, these vendor-provided certifications are based on the United States' Pharmacopeia (USP) <231 > for heavy metals which is qualitative in nature. For example, a specific brand of centrifuge tube that is

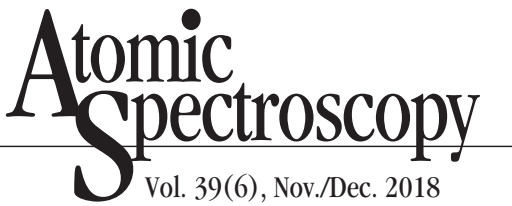

designated "metal-free" has a statement of the certificate of quality for each lot that the bulk material used to make the centrifuge tubes had heavy metals concentrations less than $1 \mathrm{ppb}$. When you are using methods with detection limits 10 or 100 times lower than $1 \mu \mathrm{g} / \mathrm{L}$, this is problematic. Other manufacturing process-related factors to consider in addition to the metals content of the bulk materials are cleanliness of the machinery used to make the equipment (stainless steel components can lead to contamination), the cleanliness of the manufacturing environment (airborne metal contaminants that may settle on the product being manufactured), and metal contamination levels of other products made within the same manufacturing environment. All of these factors along with others have an impact on the resulting metals concentrations in the final manufactured product. USP 231, which was scheduled to be deleted at the beginning of 2018, has been replaced with quantitative methods USP <232> and USP <233> (9).

This was a step in the right direction; however, it still did not address the specific problems that we experience with materials not being suitable for our biomonitoring measurements.

\section{Instrumentation}

Our laboratory uses a PerkinElmer ${ }^{\circledR}$ ELAN $^{\circledR}$ Dynamic Reaction Cell $^{\mathrm{TM}}$ (DRC ${ }^{\mathrm{TM}}$ ) II ICP-MS (PerkinElmer, Inc., Shelton, CT, USA) for screening of devices used for blood metals analysis, serum metals analysis, and the analysis of iodine and mercury in urine. We use a PerkinElmer NexION ${ }^{\circledR}$ 300D ICP-MS with Universal Cell Technol$\mathrm{ogy}^{\mathrm{TM}}$ (UCT ${ }^{\mathrm{TM}}$ ) and DRC capabilities for screening of the remaining urine metals. Both ICP-MS instruments used currently are equipped with nickel sampler and skimmer cones, a 2.0-mm quartz injector, and a quartz cyclonic spray cham- 
ber. The instrument parameters are listed in Table I. We use a SC4-DX FAST autosampler (Elemental Scientific Inc., Omaha, NE, USA) with both instruments. We use $>99.999 \%$ argon for the plasma gas. Our laboratory's use of DRC gases mirrors what is used in the actual analytical method used to analyze patient samples. We use methane and oxygen as DRC gases during the analysis of items screened for blood metals analysis, while we use ammonia as a DRC gas during testing of items screened for serum metals analysis $(4,5)$. For the urine metals screening, the ICP-MS is operated in vented mode.

\section{Sample Preparation and Analysis}

To determine the suitability of different devices for sample collection, preparation, analysis, and storage, we test an aliquot of screening solution that has been exposed to the surfaces of the device that will be exposed to a patient sample. The screening solution is typically a dilute acidic solution ( $0.5 \%$ nitric acid) or deionized water. Once the devices are received in-house for screening, scientists in the lot screening laboratory add the appropriate amount of lot screening solution to each of the 50 units. Either we pass a screening solution through the device (e.g., needles, pipette tips), or we put screening solution in the device (e.g., urine cups and cryogenic vials) and subsequently prepare an aliquot of the solution for analysis. The contact time of the solution with each unit

TABLE I

ICP-MS Instrumental Parameters for Screening Methods

\begin{tabular}{|c|c|c|c|}
\hline \multirow{2}{*}{$\begin{array}{l}\text { Parameters } \\
\text { ICP-MS }\end{array}$} & \multicolumn{3}{|c|}{ Settings Used ${ }^{\mathrm{a}}$} \\
\hline & Urine Multielement & Serum & Blood \\
\hline \multirow[t]{2}{*}{ RF Power } & $1450 \mathrm{~W}^{\mathrm{a}}(\mathrm{ELAN})$ & $1450 \mathrm{~W}^{\mathrm{a}}(\mathrm{ELAN})$ & $1450 \mathrm{~W}^{\mathrm{a}}$ (ELAN) \\
\hline & $1600 \mathrm{~W}^{\mathrm{a}}(\mathrm{NexION})$ & & \\
\hline Plasma Gas Flow & $15 \mathrm{~L} / \mathrm{min}^{\mathrm{a}}$ & $15 \mathrm{~L} / \mathrm{min}^{\mathrm{a}}$ & $15 \mathrm{~L} / \mathrm{min}^{\mathrm{a}}$ \\
\hline Auxillary Gas Flow & $1.2 \mathrm{~L} / \mathrm{min}^{\mathrm{a}}$ & $1.2 \mathrm{~L} / \mathrm{min}^{\mathrm{a}}$ & $1.2 \mathrm{~L} / \mathrm{min}^{\mathrm{a}}$ \\
\hline Nebulizer Gas Flow & $\sim 0.9-1.01 \mathrm{~L} / \mathrm{min}^{\mathrm{a}}$ & $\sim 0.8-1.00 \mathrm{~L} / \mathrm{min}^{\mathrm{a}}$ & $\sim 0.9-1.0 \mathrm{~L} / \mathrm{min}^{\mathrm{a}}$ \\
\hline Sweeps/Reading & 40 & 90 & 30 \\
\hline Readings/Replicate & 1 & 1 & 1 \\
\hline DRC Channel Gas A & & $0.5 \mathrm{~L} / \mathrm{min}$ & $0.84(\mathrm{Se})$ \\
\hline DRC Channel Gas B & & & $1.2(\mathrm{Mn}, \mathrm{Hg})$ \\
\hline Number of Replicates & 3 & 3 & 3 \\
\hline \multirow[t]{3}{*}{$\mathrm{RPq}$} & 0.25 & 0.7 & $0.6(\mathrm{Mn}, \mathrm{Hg})$ \\
\hline & & & $0.65(\mathrm{Se})$ \\
\hline & & & $0.25(\mathrm{Cd}, \mathrm{Pb}$ \\
\hline $\mathrm{RPa}$ & 0 & 0 & 0 \\
\hline \multirow[t]{2}{*}{ Dwell Time } & $\begin{array}{l}30 \mathrm{~ms}(\mathrm{Co}, \mathrm{Sr}, \mathrm{Mo}, \mathrm{Rh}, \mathrm{Cd} \\
\mathrm{Sn}, \mathrm{Sb}, \mathrm{Cs}, \mathrm{Mn}, \mathrm{Ba}, \mathrm{W}, \mathrm{Ir} \\
\mathrm{Tl}, \mathrm{Pb})\end{array}$ & $30 \mathrm{~ms}(\mathrm{Zn}, \mathrm{Cu}, \mathrm{Se})$ & $\begin{array}{l}50 \mathrm{~ms}(\mathrm{Rh}, \mathrm{Te}, \mathrm{Te}-1, \mathrm{Ir}) \\
100 \mathrm{~ms}(\mathrm{Mn}, \mathrm{Hg}, \mathrm{Se}, \mathrm{Pb})\end{array}$ \\
\hline & $100 \mathrm{~ms}(\mathrm{Pt}, \mathrm{U})$ & & $150 \mathrm{~ms}(\mathrm{Cd})$ \\
\hline Scan Mode & Peak Hopping & Peak Hopping & Peak Hopping \\
\hline Detector Mode & Dual & Pulse & Dual \\
\hline Analytes Tested & $\begin{array}{l}\mathrm{Be}, \mathrm{Co}, \mathrm{Sr}, \mathrm{Mo}, \mathrm{Cd}, \mathrm{Sb} \\
\mathrm{Cs}, \mathrm{Sn}, \mathrm{Ba}, \mathrm{Mn}, \mathrm{W}, \mathrm{Pt} \\
\text { Tl, Pb, U, As }\end{array}$ & $\mathrm{Zn}, \mathrm{Cu}, \mathrm{Se}$ & $\mathrm{Mn}, \mathrm{Hg}, \mathrm{Se}, \mathrm{Cd}, \mathrm{Pb}$ \\
\hline \multicolumn{4}{|l|}{ Sampling } \\
\hline Sample Flush & $11 \mathrm{~s},-3 \mathrm{rpm}$ & $35 \mathrm{~s},-15 \mathrm{rpm}$ & $6 \mathrm{~s},-5 \mathrm{rpm}$ \\
\hline Read Delay & $45 \mathrm{~s}-3 \mathrm{rpm}$ & $45 \mathrm{~s},-15 \mathrm{rpm}$ & $60 \mathrm{~s},-5 \mathrm{rpm}$ \\
\hline Analysis & $-3 \mathrm{rpm}$ & $-15 \mathrm{rpm}$ & $-5 \mathrm{rpm}$ \\
\hline Wash & $50 \mathrm{~s},-3 \mathrm{rpm}$ & $30 \mathrm{~s},-15 \mathrm{rpm}$ & $40 \mathrm{sec},-5 \mathrm{rpm}$ \\
\hline
\end{tabular}

\footnotetext{
${ }^{a}$ Suggested starting values only. Optimum parameters will depend on outcome of the optimization procedure and the instrument
} being used. 
differs based on the type of device being screened. For example, with needles we pass the screening solution through the needle into a prescreened evacuated blood tube. The contact time with the screening solution is identical to the contact time of blood being passed through a needle. To yield 50 specimens, we repeat the process for 49 additional needles from the same manufactured lot. For cryogenic vials, we uncap the vials, add screening solution, and recap the vial. We invert the 25 oddnumbered cryogenic vials and let the devices sit overnight. This process allows us to determine if contamination, if present, is coming from the vial (the even units that were left upright), the cap (all of the inverted vials), or both. Multiple types of devices are assessed in this manner. We determined that 8 to 12 hours is more than enough time to get surface contamination, if present, in solution.

We prepare aliquots for analysis through simple dilution methods using a Hamilton ${ }^{\circledR}$ Microlab $^{\circledR} 625^{\circledR}$ Advanced Dual Syringe diluter (Hamilton Company, Reno, NV, USA) equipped with a 5-mL dispensing syringe and a $1,000-\mu \mathrm{L}$ sampling syringe. Electronic single- channel pipettes are used for intermediate calibrator stock preparation, and a 5-place analytical balance is used to weigh out solid reagents. We take an aliquot of the solution from each of the 50 units and dilute it with diluent using the same ratio that would be used for a patient sample. We prepare a matrix blank by diluting a screening solution that is stored in prescreened containers. To preserve the correlation between the associated analytical methods used for biological specimens, we make certain that each screening analytical method is as close to the actual analytical method as possible. The reagents are prepared in a similar fashion with the exception of being prepared in water instead of the corresponding biological matrix. The preparation specifics for the solutions and controls used in these methods are listed in Table II.

Within the same analytical run, we analyze quality control materials to demonstrate the acceptability of instrument performance and to confirm the proper preparation of samples. We treat the prepared aliquots from each of the 50 units in each manufactured lot as unknowns, allowing us to quantify the metals content, if any, present in the solution. We prepare quality control materials from different lots of materials than the lots used for the preparation of calibrators. A $\pm 10 \%$ recovery limit is used for the pass/fail determination of the quality control materials used within the analytical run. If the QC materials are not within limits, the analytical run has to be repeated.

Historically, our laboratory utilized several different screening solutions. Initially, we used aqueous solutions that had the same chemical constituents as the diluents used in the methods used to analyze patient samples in the matrix of interest. We simplified the process by using a dilute acidic solution for everything, and over time, we further simplified processes by using $0.5 \%$ nitric acid as the screening solution for all analytical methods regardless of the patient sample matrix. We found that the dilute acidic solution effectively mimicked the solubility characteristics of patient samples. The screening solution, rinses, diluents, and calibrators are prepared using double-distilled concentrated (68\%$70 \%)$ nitric acid. Each bottle of double-distilled nitric acid is tested before the screening solutions, instrument rinses, and sample dilu-

TABLE II

Solutions and Calibration Standards Used in the Screening Methods for Each Matrix

\begin{tabular}{|c|c|c|c|c|}
\hline $\begin{array}{l}\text { Screening } \\
\text { Method }\end{array}$ & $\begin{array}{c}\text { Rinse } \\
\text { Composition } \\
\end{array}$ & $\begin{array}{c}\text { Diluent } \\
\text { Composition } \\
\end{array}$ & $\begin{array}{c}\text { Quality Control } \\
\text { Materials }\end{array}$ & $\begin{array}{c}\text { Volume of Sample: } \\
\text { Diluent in } \mu \mathrm{L}\end{array}$ \\
\hline Blood Metals & $\begin{array}{l}0.1 \% \mathrm{APCD}^{\mathrm{a}}, \\
0.05 \% \text { Triton- } \mathrm{X}^{\circledR}, \\
0.4 \% \mathrm{TMAH}^{\mathrm{b}}, \\
1 \% \text { EtOH in } \mathrm{DI} \mathrm{H}_{2} \mathrm{O}\end{array}$ & $\begin{array}{l}5 \mu \mathrm{g} / \mathrm{L} \mathrm{Rh}^{\mathrm{d}}, \mathrm{Ir}^{\mathrm{e}}, \\
\mathrm{Te}^{\mathrm{f}} \text { in } 0.01 \% \mathrm{APCD}^{\mathrm{a}}, \\
0.05 \% \text { Triton-X }{ }^{\circledR}, \\
0.4 \% \text { TMAH } \\
1 \% \text { EtOH in } \mathrm{DI} \mathrm{H}_{2} \mathrm{O}\end{array}$ & $\begin{array}{l}\text { Calibration Standard } 2 \\
\text { IV QC }\end{array}$ & 200:4800 \\
\hline Serum Metals & $2 \% \mathrm{HNO}_{3}{ }^{\mathrm{c}}$ in $\mathrm{DI} \mathrm{H}_{2} \mathrm{O}$ & $\begin{array}{l}10 \mu \mathrm{g} / \mathrm{L} \mathrm{Ga}^{\mathrm{h}} \\
\text { in } 0.5 \% \mathrm{HNO}_{3}{ }^{\mathrm{c}} \\
\text { in } \mathrm{DI} \mathrm{H}_{2} \mathrm{O}\end{array}$ & $\begin{array}{l}\text { Standard } 2 \\
\text { SRM } 1640 a^{i}\end{array}$ & $300: 4200$ \\
\hline Urine Metals & $2 \% \mathrm{HNO}_{3}{ }^{\mathrm{c}}$ in $\mathrm{DI} \mathrm{H}_{2} \mathrm{O}$ & $\begin{array}{l}10 \mu \mathrm{g} / \mathrm{L} \mathrm{Ga}^{\mathrm{h}}, \mathrm{Rh}^{\mathrm{d}}, \\
\mathrm{Ir}^{\mathrm{e}} \text { in } 2 \% \mathrm{HNO}_{3}{ }^{\mathrm{c}} \\
\text { in } \mathrm{DI} \mathrm{H}_{2} \mathrm{O}\end{array}$ & $\begin{array}{l}\text { Standard } 2 \\
\text { IV QC }\end{array}$ & 200:4800 \\
\hline
\end{tabular}

\footnotetext{
${ }^{\mathrm{a}}$ Ammonium pyrrolidine dithiocarbamate. ${ }^{\mathrm{b}}$ Tetramethylammonium hydroxide. ${ }^{\mathrm{c}}$ Nitric acid. ${ }^{\mathrm{d}}$ Rhodium. ${ }^{\mathrm{e}}$ Iridium. ${ }^{\mathrm{f}}$ Tellurium.

${ }^{\mathrm{g}}$ Inorganic Ventures quality control material. ${ }^{\mathrm{h}}$ Gallium. ${ }^{\mathrm{i}}$ National Institute for Standards and Technology $1640 \mathrm{a}$.
} 
ent are prepared to ensure that contamination is not being introduced with the reagents being used. In addition to testing the nitric acid used in the screening process, we test all reagents used by evaluating the counts per second obtained with each analyte when screened using the ICP-MS. Any reagent with evidence of potential contamination is not used. We also use different lots of reagents to account for variations in the analytical process.

During a period of evaluation of the current lot screening processes, we implemented a change to our typical screening approach. With metallic components such as stainless steel needles, we now use deionized water instead of $0.5 \%$ nitric acid as the screening solution. The reason for that change was to eliminate metal contamination that we attributed to leaching of metals out of the stainless steel needle that would not be leached out during the short period of contact between the blood and the needle. Additionally, since the normal $\mathrm{pH}$ of blood is between 7.36 and 7.41 , the $\mathrm{pH}$ of water more closely resembles blood than our $0.5 \%$ nitric acid screening solution which has a pH of approximately 1.3 (10). Based on this information, we implemented use of deionized water as the screening solution for all blood-metals related devices.

\section{RESULTS AND DISCUSSION}

\section{Evaluation of Lot Screening Data}

The analytical results for the analysis of aliquots from a specific manufactured lot are not the only determining factor of the acceptability of a manufactured lot of materials. Our laboratory uses the following information to determine the acceptability of a specific lot for each individual analyte of interest: the limit of detection (LOD) of the biomonitoring methods, expected population mean, the typical sam- ple volume that is collected in the device (or the known specific volume that will be used for a particular study), the amount of screening solution used when setting up the device, and the analytical results obtained via screening. The LOD is the lowest value that can be tested for a particular analyte with certainty when applying the normal analytical method for patient samples. The LODs for the analytical methods used for patient samples are derived from the analysis of matrix-matched calibration standards over at least 60 runs. The method used to calculate LODs in our laboratory is a standardized process defined by the Division of Laboratory Sciences. It accounts for both Type I and Type II errors. We use the patient sample analytical method LODs for the screening methods under the assumption that the screening LOD is lower than the LOD of the analytical method because the screening methods are aqueous and there is no matrix present.

Any screening result obtained that is greater than the LOD is logged into a spreadsheet used to report results. The expected population mean is the expected mean concentration of the analyte of interest in the population to be studied. This data is available in the most recent version of the National Report on Human Exposure to Environmental Cbemicals. The values are updated with each release of NHANES data. For newer methods where NHANES data are not available, we rely on available reference values from the literature. In instances where neither NHANES nor reference values are available, we analyze a number of patient samples via that method and calculate the mean values in that subset. The volume of sample in a device is the amount of patient sample that is either going to pass through the device or be stored in the container tested and is determined by the requestor. We give guidance to the requestors to ensure that the screening results provided reflect the intended usage of the device. Table III lists the guidelines for determining the amount of sample that the end user expects will be exposed to the device. The volume of screening solution is the amount of screening solution that passes through the devices or is aliquotted in the storage container during screening.

The presence of some levels of the analyte does not necessarily mean that the device is unsuitable for use. The maximum allowable contribution is the maximum total concentration of the analyte that can be present in the device or container and still be deemed acceptable for use. It is determined using some of the previously described factors with the following equation:

Max Allowable Contribution =

(Expected Population Mean) x (Max \% Contribution) $\mathrm{x}$ (Volume Sample in Device)

(Volume Screening Solution)

The maximum percent contribution describes the percentage of the analyte that is allowed to be present in the device tested. We set this at a default value of $10 \%$. If the calculated maximum allowable contribution is less than the LOD for the analytical method used for patient samples, then the maximum allowable contribution defaults to 1.5 times the LOD of the method.

A lot is deemed a failure if the result for any particular analyte for multiple units is above the maximum allowable contribution. If only one unit of the 50 screened fails in a lot, the laboratory supervisor can decide whether this failure should be considered an outlier. This determination is based upon specific knowledge of the analyte, such as whether it is one that we can reasonably find in the laboratory (i.e., if random contamination is possible). If the failure is deemed an outlier, the lot is identified as 
suitable for use. However, if multiple units have concentrations above the LOD in addition to one unit having a concentration above the maximum allowable contribution, the manufactured lot is marked as failing for the affected analyte(s). If no devices are above the maximum allowable contribution, we consider the lot acceptable for use by the methods tested and the analytes evaluated.

Table IV shows the number of manufactured lots of materials screened by our laboratory per NHANES cycle. The data are broken down by device type and sample matrix. In this manuscript, we provide data as early as 2001; however, the 2009-2010 NHANES cycle was the first one where we screened devices for the complete panel of metals that we currently measure. When calculating the percentage of failures screened per analyte, we take into consideration the number of lots actually tested for that analyte. For example, if we tested 10 lots during a NHANES cycle but only 5 of the lots were tested for zinc, the percentage of failures would be based solely on the 5 lots tested for zinc.

\section{Serum Metals}

Between 2002 and 2016, our laboratory screened 365 manufactured lots of materials for $\mathrm{Zn}, \mathrm{Cu}$, and/or Se to support our serum metals analyses. As shown in Table V, background contamination in the devices was as high as $1408 \mu \mathrm{g} / \mathrm{L}$ for zinc in an alcohol prep pad. The $387 \mu \mathrm{g} / \mathrm{L}$ failure was from an EDTAcontaining evacuated blood tube while the $204 \mu \mathrm{g} / \mathrm{L}$ failure was from a $0.25 \mathrm{~mL}$ microcentrifuge tube. To put this in perspective in terms of biomonitoring, the geometric mean of zinc in the U.S. population according to the 2013-2014 cycle of NHANES data was $80.4 \mu \mathrm{g} / \mathrm{L}$. The three highest copper failures were from needles and cryovials, and the selenium failures were from a manufactured lot of needles. While the geometric means for copper and selenium in the U.S. population for the 2013-2014 NHANES cycle were $115 \mu \mathrm{g} / \mathrm{L}$ and $128 \mu \mathrm{g} / \mathrm{L}$, respectively the LODs were $2.5 \mu \mathrm{g} / \mathrm{L}$ and $4.5 \mu \mathrm{g} / \mathrm{L}$, respectively.

\section{Urine Metals}

Between 2002 and 2016, our laboratory screened 404 manufactured lots of materials for the urine metals which include As, Ba, Be, Cd, Cs, $\mathrm{Co}, \mathrm{Pb}, \mathrm{Mn}, \mathrm{Mo}, \mathrm{Pt}, \mathrm{Sr}, \mathrm{Tl}, \mathrm{Sb}, \mathrm{Sn}$, $\mathrm{W}$, and $\mathrm{U}$. The highest screening results from the individual lots screened from 2002 through 2016 are shown in Table VI for each analyte. In nearly all cases, the failures were higher than the NHANES geometric mean for the U.S. population and the method LOD for each analyte; in most cases significantly higher. The two highest failures for barium are from two separate lots of wipes. It should be noted that there were multiple failures within each of these lots. The highest failures for antimony and manganese were also from screened lots of wipes. The elevated lead failures were from urine cups. Overall, the highest failures shown were from a wide array of types of devices centrifuge tubes, urine cups, wipes, cryovials, pipette tips, and urine bags. In terms of all failures seen, there were failures across all the types of devices that have been

TABLE III

Volume of Patient Sample Expected to Come Into Contact With Different Types of Devices

\begin{tabular}{ll}
\hline Type of Device & Typical Specimen Volume \\
\hline $\begin{array}{l}\text { Evacuated blood and serum tubes } \\
\text { and micro-collection vials }\end{array}$ & Full volume of the collection device \\
Cryogenic vials & $\begin{array}{l}\text { Smallest volume that you expect } \\
\text { the vials will contain }\end{array}$ \\
Gauze and alcohol prep pads & $\begin{array}{l}\text { Volume of blood expected to be } \\
\text { collected in the capillary blood } \\
\text { collection procedure }\end{array}$
\end{tabular}

Syringes and transfer pipettes

Needles and luer adapters

Collection cups and centrifuge tubes

Lancets
Half of the full volume of the syringe

Full volume of the smallest blood tube that would be used

Half of the maximum volume unless a specific volume is known

Volume of blood expected to be collected in the capillary blood collection procedure

\section{Reasoning}

The full volume will be drawn due to the vacuum

Provides a more conservative estimate

Use of the smallest volume to get the most conservative estimate of the effect of contribution

Used for a wide array of volumes provides a conservastive estimate

The full volume will be drawn due to the vacuum

Provides a more conservative estimate 
TABLE IV

The Number of Manufactured Lots Screened for Each Type of Device for Each Matrix During the NHANES Cycle Years from 2001 Through 2016

\begin{tabular}{|c|c|c|c|c|c|c|c|c|}
\hline \multirow{2}{*}{$\begin{array}{ll}\text { Sample } & \text { Type of } \\
\text { Type } & \text { Device }\end{array}$} & \multicolumn{8}{|c|}{ NHANES Cycle Years } \\
\hline & $2001-2002$ & 2003-2004 & 2005-2006 & $2007-2008$ & 2009-2010 & 2011-2012 & 2013-2014 & 2015-2016 \\
\hline \multicolumn{9}{|l|}{ Urine } \\
\hline Transfer pipettes & & 1 & 1 & & 4 & 6 & 20 & 5 \\
\hline Cryogenic vials & 2 & 1 & 5 & 8 & 8 & 25 & 48 & 39 \\
\hline Pipette tips & & 1 & & & 2 & 14 & 13 & 8 \\
\hline Urine cups & 4 & 4 & 2 & 9 & 9 & 9 & 28 & 28 \\
\hline Centrifuge tubes & 3 & 4 & 2 & 3 & 2 & 6 & 12 & 11 \\
\hline Syringes & & & & & 8 & & 1 & 4 \\
\hline Bags & & & & & 1 & 2 & 8 & 2 \\
\hline Wipes & & & & & & 1 & 2 & 11 \\
\hline Miscellaneous & & & & 1 & 8 & 3 & 2 & 3 \\
\hline \multicolumn{9}{|l|}{ Blood } \\
\hline Alcohol pads & 1 & 5 & 3 & 1 & & 2 & 2 & 2 \\
\hline Blood bags & & & & & 7 & 1 & & \\
\hline Centrifuge tubes & & 1 & & 3 & 4 & 2 & 3 & 4 \\
\hline Cryogenic vials & 3 & 3 & 3 & 2 & 5 & 5 & 15 & 15 \\
\hline Lancets & & & 4 & & 4 & & & 5 \\
\hline Luer adapters & & 4 & 4 & 3 & 4 & 1 & 1 & 7 \\
\hline Miscellaneous & & & & & 8 & 5 & 2 & 3 \\
\hline Needles & & 8 & 17 & 21 & 35 & 11 & 42 & 30 \\
\hline Pipette tips & & & & & 4 & 5 & 2 & 1 \\
\hline Pipettes & & 1 & 1 & & 2 & 4 & 13 & 2 \\
\hline Syringes & & 2 & 4 & & 7 & 1 & 7 & 3 \\
\hline Evacuated blood tubes & s 5 & 19 & 15 & 9 & 27 & 13 & 41 & 34 \\
\hline \multicolumn{9}{|l|}{ Serum } \\
\hline Needles & & 3 & 7 & 8 & 20 & 10 & 41 & 30 \\
\hline Lancets & & & 2 & & 2 & & & \\
\hline Luer adapters & & & & & 1 & 1 & 1 & 8 \\
\hline Alcohol pads & & 2 & 1 & & & 2 & 2 & \\
\hline Transfer pipettes & & 1 & 1 & & 2 & 4 & 13 & 2 \\
\hline Centrifuge tubes & 1 & 1 & & 2 & 3 & 3 & 3 & 5 \\
\hline Pipette tips & & & & & & 3 & & 4 \\
\hline Cryogenic vials & 2 & 1 & 4 & 3 & 6 & 10 & 22 & 21 \\
\hline Syringes & & 1 & 6 & & & & 7 & 4 \\
\hline Evacuated serum tubes & s 4 & 3 & 7 & 5 & 11 & 14 & 17 & 17 \\
\hline Miscellaneous & 1 & & & & & 2 & 2 & 6 \\
\hline Total & 26 & 66 & 89 & 78 & 194 & 165 & 370 & 314 \\
\hline
\end{tabular}




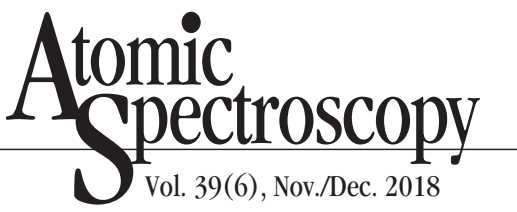

TABLE V

Screening Data for Serum Metals 2002-2016 - Highest Failures

\begin{tabular}{lccccc}
\hline Metal & $\begin{array}{c}\text { Highest } \\
\text { Failure } \\
(\mu \mathrm{g} / \mathrm{L})\end{array}$ & $\begin{array}{c}\text { 2nd Highest } \\
\text { Failure } \\
(\mu \mathrm{g} / \mathrm{L})\end{array}$ & $\begin{array}{c}\text { 3rd Highest } \\
\text { Failure } \\
(\mu \mathrm{g} / \mathrm{L})\end{array}$ & $\begin{array}{c}\text { 2013-2014 } \\
\text { NHANES } \\
\text { Geometric Mean }(\mu \mathrm{g} / \mathrm{L})\end{array}$ & LOD $^{\mathrm{a}}$ \\
\hline Zinc & 1410 & 387 & 204 & 80.4 & 2.9 \\
Copper & 8.49 & 17.1 & 14.0 & 115 & 2.5 \\
Selenium & 25.4 & 23 & N/A & 128 & 4.5 \\
\hline
\end{tabular}

${ }^{a}$ This LOD was used during the 2013 to 2014 NHANES cycle.

TABLE VI

Screening Data for Urine Metals 2002-2016 - Highest Failures

\begin{tabular}{lcccrr}
\hline Metal & $\begin{array}{c}\text { Highest } \\
\text { Failure } \\
(\mu \mathrm{g} / \mathrm{L})\end{array}$ & $\begin{array}{c}\text { 2nd Highest } \\
\text { Failure } \\
(\mu \mathrm{g} / \mathrm{L})\end{array}$ & $\begin{array}{c}\text { 3rd Highest } \\
\text { Failure } \\
(\mu \mathrm{g} / \mathrm{L})\end{array}$ & $\begin{array}{c}\text { 2013-2014 } \\
\text { NHANES } \\
\text { Geometric Mean }(\mu \mathrm{g} / \mathrm{L})\end{array}$ & LOD $^{\mathrm{a}}$ \\
\hline Antimony & 125 & 98.6 & 30.1 & 0.043 & 0.022 \\
Arsenic & 17.2 & 7.14 & 2.15 & 6.29 & 0.26 \\
Barium & 2170 & 157 & 84.1 & 1.09 & 0.06 \\
Beryllium & 2.66 & 2.6 & 0.331 & $\mathrm{~b}$ & 0.072 \\
Cadmium & 15.2 & 4.2 & 0.636 & 0.124 & 0.036 \\
Cesium & 6.03 & $\mathrm{~N} / \mathrm{A}$ & $\mathrm{N} / \mathrm{A}$ & 3.94 & 0.086 \\
Cobalt & 9.92 & 7.29 & 4.38 & 0.391 & 0.023 \\
Lead & 96.4 & 64.8 & 64.8 & 0.277 & 0.03 \\
Manganese & 169 & 157 & 77.1 & $\mathrm{~b}$ & 0.13 \\
Molybdenum & 1.40 & 0.971 & $\mathrm{~N} / \mathrm{A}$ & 33.9 & 0.8 \\
Platinum & 0.701 & 0.265 & 0.18 & $\mathrm{~b}$ & $0.009^{\mathrm{c}}$ \\
Strontium & 237 & 174 & 153 & 81.2 & 2.34 \\
Thallium & 0.992 & 0.212 & 0.067 & 0.141 & 0.018 \\
Tin & 9.26 & 8.92 & 4.36 & 0.433 & 0.09 \\
Tungsten & 1.35 & 0.413 & 0.41 & 0.059 & 0.018 \\
Uranium & 0.164 & 0.135 & 0.12 & 0.005 & 0.002 \\
\hline
\end{tabular}

a The LOD is the one used during the 2013 to 2014 NHANES cycle.

$\mathrm{b}$ The geometric mean was not calculated due to an insufficient number of results above the limit of detection.

c The LOD for platinum was from the 2009-2010 NHANES cycle.

screened for urine metals across the years. Urine devices are also screened for mercury and iodine when needed, but we have rarely seen failures for those metals over the years. Chromium and nickel are two recent additions to the urine metals screening panel; however, they were not discussed due to insufficient data.

\section{Blood Metals}

Between 2002 and 2016, our laboratory screened 533 manufactured lots of materials for $\mathrm{Mn}, \mathrm{Hg}, \mathrm{Cd}$, Se, and/or $\mathrm{Pb}$ to support our blood metals analyses. Background contamination for manganese in the lots screened was as high as $924 \mu \mathrm{g} / \mathrm{L}$ in one screened lot of needles, while the second and third highest failures were from cryovials and gauze pads. The two mercury failures were from a manufactured lot of pipette tips and one lot of transfer pipettes. The $62.1 \mu \mathrm{g} / \mathrm{L}$ selenium failure was from a transfer pipette. All of the cadmium failures were from one specific lot of gauze pads, while the lead failures were from
EDTA-containing evacuated blood tubes, vials, and alcohol prep pads. All of the failures listed in Table VII were above the laboratory LOD for these metals, and all except selenium were also above the geometric means for U.S. population for the 2015 to 2016 NHANES cycle.

\section{CONCLUSION}

Testing a representative sample of each manufactured lot (50 items from each lot) can detect contamination that would significantly 
TABLE VII

Screening Data for Blood Metals 2002-2016 - Highest Failures

\begin{tabular}{|c|c|c|c|c|c|}
\hline Metal & $\begin{array}{l}\text { Highest } \\
\text { Failure } \\
(\mu \mathrm{g} / \mathrm{L})\end{array}$ & $\begin{array}{c}\text { 2nd Highest } \\
\text { Failure } \\
(\mu \mathrm{g} / \mathrm{L})\end{array}$ & $\begin{array}{l}\text { 3rd Highest } \\
\text { Failure } \\
(\mu \mathrm{g} / \mathrm{L})\end{array}$ & $\begin{array}{c}\text { 2015-2016 } \\
\text { NHANES } \\
\text { Geometric Mean }(\mu \mathrm{g} / \mathrm{L})\end{array}$ & LOD \\
\hline Manganese & 924 & 180 & 74.8 & 9.59 & 0.99 \\
\hline Mercury & 0.465 & 0.35 & N/A & 0.678 & 0.28 \\
\hline Selenium & 62.1 & N/A & N/A & 191 & 24.5 \\
\hline Cadmium & 1.33 & 1.25 & 1.19 & 0.238 & 0.1 \\
\hline Lead & $20.9^{\mathrm{a}}$ & $12.7^{\mathrm{a}}$ & $6.98^{a}$ & $0.820^{\mathrm{a}}$ & $0.07^{\mathrm{a}}$ \\
\hline
\end{tabular}

${ }^{\mathrm{a}} \mathrm{Lead}$ is in $\mu \mathrm{g} / \mathrm{dL}$.

affect the analytical results obtained from using the materials. Our laboratory has generated over 15 years of data that validate the necessity to continue lot screening efforts. Contamination is spurious enough to validate the need for screening all manufactured lots used in the lab. Using contaminated supplies for collection or analysis has a trickledown effect on the entire analytical process. Contamination at any point in the process produces falsely elevated patient results, leading to incorrect reference range determinations with biomonitoring data. These incorrect ranges can result in invalid assumptions. In instances where untested devices are used in either the collection, sample processing, analytical processing, or storage, any elevated results could be due to contamination and may not be truly representative of the patient samples. If contamination is identified in collection materials after analytical results have already been obtained, the results will be invalidated; therefore, it is imperative that screening is performed prior to items being used at any step of the analytical process: sample collection, sample analysis, or sample storage.

\section{Conflicts of Interest:}

The authors (Cynthia D. Ward, Reba J. Williams, Katelyn Mullenix, Kristy Syhapanha, Robert L. Jones, and Kathleen Caldwell) have no conflicts of interest relevant to this article to disclose.

Received May 24, 2018.

\section{REFERENCES}

1. R. Y. Wang, K. L. Caldwell, and R. L. Jones, J. Med. Toxicol. 10, 232 (2014)

2. Centers for Disease Control and Prevention. Fourth Report on Human Exposure to Environmental Chemicals, Updated Tables (March 2018) Atlanta, GA: U.S. Department of Health and Human Services, Centers for Disease Control and Prevention.

3. K. L. Caldwell, P. Y. Cheng, J. M. Jarrett, A. Makhmudov, K. Vance, C. D. Ward, R. L. Jones, and M. E. Mortensen, Pediatrics, 140(2): e20170272 (2017).

4. J. M. Jarrett, R. L. Jones, K. L. Caldwell, and C. P. Verdon, At. Spectrosc. 28(4), 113 (2007).

5. D. R. Jones, J. M. Jarrett, D. S. Tevis, M. Franklin, N. J. Mullinix, K. L. Wallon, C. D. Quarles, K. L. Caldwell, and R. L. Jones, Talanta 162, 114 (2017).

6. I. Rodushkin and F. Odman. J. Trace Elem. Med. Biol. 15, 40 (2001).
7. Clean Air Technology, Inc., What is a Cleanroom? (2017).

http://www.cleanairtechnology. com/cleanroom-classificationsclass.php. (Accessed 11 Nov. 2017.)

8. W. D. Johnson, Biostatistics, Reinhold Publishing Corporation (1966).

9. K. Zaidi, USP chapters $<232>$ and $<233>$ implementation strategy PowerPoint presentation. https://www.fda.gov/downloads/D rugs/NewsEvents/UCM517456.pdf. (Accessed 11 Oct 2017.)

10. J. B. Henry, Clinical diagnosis and management by laboratory methods, 17th edition, W.B. Saunders Company (1984). 